\title{
Pricing competition and channel coordination in the tourism supply chain with optional tours
}

\author{
QIANG GUO \\ Tourism College, Hainan University, Haikou, PR China. \\ E-mail: raymondguobot@botmail.com.
}

YE SHI

School of Management, University of Science and Technology of China, Hefei, PR China. E-mail: hecralies@gmail.com.

JUNFENG DONG

School of Management, Hefei University of Technology, Hefei, PR China.

E-mail: jfdong4@ustc.edu.cn.

\section{XiAOLONG GUO}

School of Management, University of Science and Technology of China, 96 Jinzhai Road, Hefei, Anbui Province 230026, PR China. E-mail: gxl@mail.ustc.edu.cn.

(Corresponding author.)

\section{CHRIS K. ANDERSON}

School of Hotel Administration, Cornell University, Ithaca, New York, USA. E-mail: cka9@cornell.edu.

The authors consider a tourism supply chain that consists of a tour operator in the source market and a local operator at the destination. The tour product is composed of predesigned tours and optional tours. Consumers are sensitive to the price and the availability of optional tours, represented as the ratio of optional tours. The authors analyse how the ratio of optional tours to predesigned tours affects each player's equilibrium decisions given three different consumer

The authors are grateful to the anonymous referees and the Editor for their valuable comments and feedback. This work was supported by the National Natural Science Foundation of China (Nos 71161008 and 71301037) and the Foundation for Innovative Research Groups of the National Natural Science Foundation of China (No 71121061). Xiaolong Guo would also like to thank the China Postdoctoral Service Foundation (No 2014MS60523) for its support. 
attitudes towards optional tours. They find that when the channel is coordinated and the ratio of optional tours is sufficiently large, the local operator may reduce commissions. To curb the impacts of lowering commissions, the authors introduce a tax mechanism aimed at optional tours. Numeral examples are provided to illustrate the pricing impacts of optional tours.

Keywords: tourism supply chain management; optional tours; overlow commission; tax mechanism

In today's tourism industry package tours can be generally categorized as either predesigned or optional tours. Broadly speaking, the content of optional tours comprises entertainment activities, shopping and sightseeing, and so on. At the initial stage of development, optional tours are added as extensions to the predesigned content of package tours with tourists participating in these additional activities if (free) time permits (Enoch, 1996). For the tourist optional tours add flexibility to classic packaged tours and offer them opportunities to choose what they prefer. For tour operators optional tours provide additional revenue. Since optional tours benefit both customers and suppliers, they have become one of the key components of package tours in recent years.

Optional tours often play a role as distinguishing features in attracting tourists who prefer more flexibility in choosing tour products. In addition, the marginal profit of optional tours is often greater than that of predesigned tours. As a result, tour operators are motivated to increase their offerings of optional tours. Although optional tours play a significant role in contemporary tourism operations, there are limited academic studies on their effective use. To fill this gap, we provide here a simple but insightful tourism supply chain model with both predesigned and optional tours. Specifically, we discuss the role of optional tours under a typical tourism supply chain, which consists of a tour operator and a local in-market operator. Together they provide the tourists with a package tour composed of a predesigned tour and optional tours. The tour operator in the source market determines the price of the predesigned portion then advertises/sells the product to tourists. The local operator in the destination is responsible for providing tour services and decides the commission price. Our paper makes three main contributions, summarized below.

(a) Through an equilibrium analysis we show how optional tours affect system demand and profit. In particular, we show that an increase in optional tours can both benefit and hurt each player depending on tourist preferences.

(b) Quantity discount contracts are introduced into the tourism supply chain to achieve coordination. We identify the conditions under which the commission price that the local operator earns for providing predesigned tour service is not greater than the corresponding costs. In other words, the local operator makes zero or minus profit by providing predesigned tour service in that case. In such an extreme case, the local operator makes positive profits only from optional tours, which completely reveals the meaningful role of optional tours. In this paper, that case is referred as the 
over-low commission (OLC) case. A counterpart of OLC in practice is zero or minus commission (Zhang et al, 2009b), which often occurs in the Chinese tourism supply chain. Our analysis shows that coordination might be a driver of OLC and a large proportion of optional tours are fundamental conditions of OLC.

(c) In practice, zero or minus commission is often accompanied by cheating and threatening, which leads to serious tourist dissatisfaction and harms the development of the Chinese tourism industry (Zhang et al, 2009a). Hence, we present a further discussion on a tax aimed at optional tours to curb OLC. The model analysis verifies that OLC can be curbed by adjusting the tax rate. Through numerical examples we show that local government can control zero or minus commission by adjusting the tax rate.

In the following section we highlight the relevant literature. Then we provide a description of the model in the subsequent section. The equilibrium analysis of the channel is presented after the model description. We then provide a discussion on tax rate impacts on coordination, followed by numerical examples and conclusions.

\section{Literature review}

First, we review some empirical papers that emphasize the critical role of optional tours. Enoch (1996) presents a comparison study on contents of package tours illustrating how optional tours are viewed as an extension to the predesigned content of package tours. Wang et al (2000) identify optional tours as one of the three main critical service features in package tours. They show that fees for optional tours are one of the main reasons for customer dissatisfaction. In addition, non-participation by guides in optional tours contributes towards dissatisfaction. For further studies concerning tour guides see Mak et al (2011) and Wang et al (2010).

Since our research is closely related to competitive pricing in the tourism supply chain, we discuss a few related papers. Lee and Jang (2013) utilize a spatial econometric model to study asymmetric price competition among hotels differentiated in terms of quality. Their research confirms that those lowerquality hotels are forced to discount deeper in the low season. Song et al (2009) consider a pricing game between a theme park and a tour operator. In their paper, a quantity discount contract is used to coordinate the channel and the theme park shares a large part of the coordinated profit owing to its dominant role in the coordination. Dong et al (2012) study pricing competition among three players: a tour operator; a mature destination; and an underdeveloped destination. They focus on the underdeveloped destination's pricing decisions under different modes of cooperation. A comparative analysis of coordination modes provides insight into the development of the underdeveloped destination. In addition to price competition within traditional business contexts, more recent efforts have focused on Internet or e-commerce enabled price competition. For example, Ling et al (2011), Ling et al (2012) and Guo et al (2013) illustrate price competition between a hotel and a third-party website. 
In particular, Guo et al (2013) consider price competition between multiple hotels and a single third-party website that distributes the hotels' rooms online. They show the existence and uniqueness of the equilibrium solutions. Other papers illustrate the impacts of both price and quantity competition within a tourism context; see Yang et al (2009), Huang et al (2010a), Huang et al (2010b), Dong et al (2011), Huang et al (2012) and Guo and He (2012).

Finally we summarize relevant literature on zero or negative commissions. Zhang et al (2009b) define zero or minus commissions as a pricing scheme between local operators and tour operators, in which local operators charge zero or minus commission. Consequently, the price of the tour products is extremely low and mass tourists are attracted to purchase. However, when tourists arrive in the destinations, they are forced to consume excessive optional tours by local operators, which lead to considerable tourist dissatisfaction. Zhang et al (2009b) identify nine factors that contribute to zero commission and their resulting tourist dissatisfaction. Besides these empirical studies, Zhang et al (2009a) study the mechanism of zero or minus commission based on a game theoretic approach. In their paper, a Nash equilibrium model is applied to explain the game between two local operators. Their research indicates that zero or minus commission has a tremendous negative impact on all of the stakeholders. As an example of the attention paid to zero commission, the Chinese government has defined zero or minus commission as occurring when a tour operator's cost of providing the tour service is no less than the corresponding commission price (see http://www.hainan.gov.cn/data/hnzb/2006/06/586/). This is consistent with our definition of OLC.

\section{The problem}

We consider a tourism supply chain that comprises a tour operator selling package tour products in the source market and a local operator supplying tour services in the destination. The package tour product is composed of a single predesigned tour and a single optional tour. The tour operator determines the price, $p$, for the predesigned part of the package tours and charges no fee for the optional part, the operational cost of the tour operator is $c_{\text {r }}$. The local operator determines commission price $w$ charged to the tour operator for the predesigned tour and supplies the tourists with the optional tours at price $\alpha p$, where $\alpha(>0)$ is a constant for a certain type of package tour and stands for the ratio of the optional tours to the predesigned tours. In particular, the constant $\alpha$ is predetermined by the local operator according to the expected revenue of the predesigned tours and the optional tours before the package tours are sold. Moreover, the local operator's cost of predesigned tour services is $c_{l}$ and that of optional tour services is $c_{l o}$. The event sequence of the decision-making process in the tourism supply chain is: (a) The local operator decides the predesigned tour and optional tour, as well as the ratio of optional tours to predesigned tours, $\alpha$. (b) The local operator determines the commission price $w$ for the predesigned tour. (c) Then the tour operator decides the price $p$ for the predesigned tour and sells the packaged tours. (d) The local operator supplies the predesigned tour for tourists and provides the optional tour at price $\alpha p$ for the tourists who participate in optional tours. 
Tourists make purchase decisions according to the expected utility of travelling, which is defined as follows:

$$
U=v+\alpha \theta-p-\gamma t
$$

where $v$ is the basic utility (homogeneous for every tourist) that a tourist receives from consuming the package tour products; and $\alpha \theta$ represents the utility of consuming optional tours, where $\theta$ represents the attitude of the tourists to the optional tour (preference, aversion and insensitivity). A tourist with $\theta>0$ indicates positive utility towards optional tours, similarly, $\theta<0$ indicates an aversion and $\theta=0$ an indifference towards optional tours. Additionally, utility is decreased as a result of the purchasing price, $p$, and other expenses (such as time or energy), $t$, tourists experience as a result of participation. For simplicity we assume that, $t>0$ is identical for all tourists. Moreover, we introduce $\gamma$ to represent the diverse attitudes of the tourists to this expense. Where $\gamma$ is assumed to follow a uniform distribution with density function $f(x)$ and $x \in[0, \rho]$.

The tourists purchase the package tours if and only if their expected utilities are non-negative $(U \geq 0)$. Then the demand for package tours can be obtained as follows:

$$
q=\frac{Z}{\rho} \int_{0}^{(v p+\theta \alpha) / t} f(x) d x=\frac{Z}{\rho}\left(\frac{v-p+\theta \alpha}{t}\right)
$$

where $Z$ is the size of the tourism market.

Let $A=Z /(\rho t)$, then Equation (2) can be rewritten as:

$$
q=A(v-p+\theta \alpha) \text {. }
$$

Further, we assume that there is $\lambda(0 \leq \lambda \leq 1)$ proportion of total tourists attracted to consuming the optional tours. Thus, the demand of optional tours is $\lambda q$. We study each player's equilibrium pricing decisions in a non-cooperative and full information setting.

\section{Analysis}

In this section, we derive each player's equilibrium pricing decision and profit. Then, analysis of equilibrium profits reveals how optional tours affect each player's decision making. In particular, we study each player's equilibrium profit with regard to optional tours. The results provide insight into how to adjust optional tour composition according to tourists' attitudes towards optional tours (see Propositions 1 and 2). To study OLC we present coordination analysis in the next subsection. Specifically, quantity discount contracts are introduced to coordinate the channel (see Proposition 3). Further discussion on the contracts not only identifies the conditions under which the OLC happens (see Proposition 4), but also shows that optional tours are fundamental conditions of OLC (see Corollary 1). 
Let $\pi_{t o}$ be the tour operator's profit and $\pi_{l o}$ be the local operator's profit. Then we have:

$$
\begin{aligned}
& \pi_{l \prime}=A(v-p+\theta \alpha)\left(w-c_{l}+\lambda\left(\alpha p-c_{l \prime}\right)\right), \\
& \pi_{l^{\prime \prime}}=A(v-p+\theta \alpha)\left(p-w-c_{l}\right) .
\end{aligned}
$$

Define $c_{e}=c_{l}+c_{t}+\lambda c_{l,}$ as the average cost of serving a tourist across the tourism supply chain. A sufficient condition to guarantee non-negative equilibrium demand $\left(q^{*}\right)$ is that $v>c_{e}$ (this condition holds in all the subsequent sections). Furthermore, when $\theta<0, \alpha$ should satisfy $0<\alpha<\hat{\alpha}_{1}$ to guarantee that $q^{*}>0$. Here:

$$
\hat{\alpha}_{1}=-\frac{\theta+\lambda v+\sqrt{(\theta-\lambda v)^{2}+4 \theta \lambda_{e}}}{2 \theta \lambda} .
$$

By using backwards induction, we, first, derive the equilibrium price for the predesigned tour of package tours charged by the tour operator:

$$
p^{*}=\frac{v+\alpha \theta+c_{t}+w}{2} .
$$

By substituting Equation (7) into $\pi_{l l}$, we can get $\pi_{l 0}(w)$. Since $\partial^{2} \pi_{l 0}(w) / \partial w^{2}=$ $-A(2+\alpha \lambda) / 2<0, \pi_{l o}(w)$ is concave in $w$. Then the first order condition yields the local operator's equilibrium commission price $\left(w^{*}\right)$ for the predesigned tour:

$$
w^{*}=\frac{v+\alpha \theta+c_{e}}{2+\alpha \lambda}-c_{i}
$$

From Equation (8) we can see that the equilibrium commission price $\left(w^{*}\right)$ is increasing in the proportion of optional tours $(\alpha)$ when $\theta>\lambda\left(c_{e}+v\right) / 2$; otherwise, the equilibrium price is decreasing with $\alpha$. In other words, only when the tourists in the market have sufficient optional-tour-preference, the local tour operator can increase the commission price by increasing the proportion of optional tours. According to Equations (3) and (8) equilibrium demand $\left(q^{*}\right)$ is:

$$
q^{*}=A \frac{(\alpha \theta+v)(1+\alpha \lambda)-c_{e}}{2(2+\alpha \lambda)} .
$$

From Equation (9) we can see that the equilibrium demand is decreasing with the average cost $c_{e}$ and increasing with the proportion of optional tours $\alpha$ when $\theta>0$. Therefore, tourists have positive optional tour preference, as an increase in $\alpha$ attracts tourists, increasing demand for package tours.

Finally, the tour operator's and the local operator's equilibrium profits can be obtained as follows: 


$$
\begin{aligned}
& \pi_{l n}^{*}=A \frac{\left((\alpha \theta+v)(1+\alpha \lambda)-c_{e}\right)^{2}}{4(2+\alpha \lambda)^{2}}, \\
& \pi_{l n}^{*}=A \frac{\left((\alpha \theta+v)(1+\alpha \lambda)-c_{e}\right)^{2}}{4(2+\alpha \lambda)} .
\end{aligned}
$$

From Equations (10) and (11) we analyse the relationship between the proportion of the optional tours and each player's equilibrium profit.

Proposition 1. If tourists have positive optional tour preference $(\theta>0)$, both the local operator's equilibrium profit $\left(\pi_{l n}^{*}\right)$ and the tour operator's equilibrium profit $\left(\pi_{t n}^{*}\right)$ increase with the proportion $(\alpha)$. (Please refer to the Appendix for all proofs.)

Proposition 2. If tourists are averse to optional tours $(\theta<0)$, with

$$
\hat{\alpha}_{2}=-\left(9 \theta+\lambda v+\sqrt{(9 \theta+\lambda v)^{2}-12 \theta\left(4 \theta+\lambda\left(c_{e}+3 v\right)\right)}\right) /(6 \theta \lambda),
$$

and

$$
\hat{\alpha}_{3}=-\left(2 \theta+\sqrt{\theta\left(2 \theta-\lambda\left(c_{e}+v\right)\right)}\right) /(\theta \lambda),
$$

the following properties hold.

(a) If $\theta \leq-\lambda\left(c_{e}+3 v\right) / 4$, then the local operator's equilibrium profit $\left(\pi_{l,}^{*}\right)$ decreases with the proportion $(\alpha)$ in $\left(0, \hat{\alpha}_{1}\right)$.

(b) If $-\lambda\left(c_{e}+3 v\right) / 4<\theta<0$ and $v>\max \left\{c_{e},\left(\theta+2 \sqrt{-\theta} c_{e}\right) / \lambda\right\}$, then the local operator's equilibrium profit $\left(\pi_{l n}^{*}\right)$ increases with the proportion in $\left(0, \hat{\alpha}_{2}\right]$ and then decreases in $\left[\hat{\alpha}_{2}, \hat{\alpha}_{1}\right)$.

(c) If $\theta \leq-\lambda\left(c_{e}+v\right) / 2$, then the tour operator's equilibrium profit $\left(\pi_{t n}^{*}\right)$ decreases with the proportion in $\left(0, \hat{\alpha}_{1}\right)$.

(d) If $-\lambda\left(c_{e}+v\right) / 2<\theta<0$ and $v>\max \left\{c_{e},\left(\theta+2 \sqrt{-\theta} c_{e}\right) / \lambda\right\}$, then the tour operator's equilibrium profit $\left(\pi_{t \prime}^{*}\right)$ increases with the proportion in $\left(0, \hat{\alpha}_{3}\right]$ and decreases in $\left[\hat{\alpha}_{3}, \hat{\alpha}_{1}\right)$.

Proposition 1 indicates that both the local operator and the tour operator are motivated to increase the mix of optional tours if tourists in the source market have positive optional tour preference. However, if tourists are optional tour averse (Proposition 2), the mix of optional tours depends on the extent of tourists' aversion. Specifically, both the local operator and the tour operator are likely to decrease optional tours if tourists are sufficiently averse $\left(\theta \leq-\lambda\left(c_{e}+3 v\right) / 4\right)$. If tourists are only slightly averse to optional tours $\left(-\lambda\left(c_{p}+v\right) / 2<\theta<0\right)$, there is interval $\left(\left[0, \min \left\{\hat{\alpha}_{2}, \hat{\alpha}_{3}\right\}\right]\right)$ in which the increase in optional tours Pareto benefits the two players. In other words, both of players are motivated to increase the proportion if the proportion lies in the interval. However, in $\left[\min \left\{\hat{\alpha}_{2}, \hat{\alpha}_{3}\right\}, \max \left\{\hat{\alpha}_{2}, \hat{\alpha}_{3}\right\}\right]$, increase in the proportion benefits one player while simultaneously hurting the other. As a result, the ratio of optional tours is likely to be determined by the player who has stronger bargaining 
power. In the rest of the interval, an increase in proportion decreases both players' profits. Based on the above analysis, we conclude the following.

Insight 1. In the full equilibrium setting, how to adjust the ratio of optional tours $(\alpha)$ depends on tourists' attitude in optional tours $(\theta)$. Specifically:

(a) if tourists have optional tour preference (Proposition 1), then both the local operator and the tour operator intend to increase the mix of optional tours;

(b) if tourists are sufficiently averse to optional tours (property (a) in Proposition 2), an increase in the proportion hurts the two players' profit; and

(c) if tourists are only slightly averse to optional tours (property (d) in Proposition 2), there exists an interval in which increases in optional tour composition benefit both the tour operator and local operator.

\section{Coordination analysis}

Here we consider a coordination mechanism for the tourism supply chain. From Equations (4) and (5), we can obtain the total profit for the supply chain:

$$
\Pi(p)=A(v-p+\theta \alpha)\left(p-c_{l}-c_{t}+\lambda\left(\alpha p-c_{l p}\right)\right) .
$$

Since $\partial^{2} \Pi(p) / \partial p^{2}=-2(1+\alpha \lambda)<0, \Pi(p)$ is concave in $p$. The first-order condition yields the chain's optimal retail price of the predesigned tour of the package $\left(p^{\circ}\right)$ :

$$
p^{\circ}=\frac{\alpha \theta+v}{2}+\frac{c_{e}}{2(1+\alpha \lambda)} .
$$

In the coordinated scenario, the optimal price is increasing in the proportion of optional tours when $\theta>\lambda c_{\varepsilon} /(1+\alpha \lambda)^{2}$; otherwise, the optimal price is decreasing in the proportion of optional tours. Meanwhile, the chain's optimal demand $\left(q^{\circ}\right)$ is:

$$
q^{\circ}=A\left(\frac{\alpha \theta+v}{2}-\frac{c_{e}}{2(1+\alpha \lambda)}\right),
$$

and the optimal profit $\left(\Pi^{\circ}\right)$ is:

$$
\Pi^{\circ}=\frac{A\left((\alpha \theta+v)(1+\alpha \lambda)-c_{e}\right)^{2}}{4(1+\alpha \lambda)} .
$$

Several empirical studies (for example, Zhang and Murphy, 2009; Schiff and Becken, 2011) show that discount policies are widely adopted in tourism industry. Thus, we employ quantity discount contracts to achieve channel coordination. 
Proposition 3. The tourism supply chain can be coordinated under the following quantity discount contracts:

$$
w(q)=-c_{i}+\phi c_{i}+(1-\phi(1+\alpha \lambda))(v+\theta \alpha-q / A),
$$

where $(1+\alpha \lambda) /(2+\alpha \lambda)^{2} \leq \phi \leq 1 /(2+\alpha \lambda)$.

Moreover, $\pi_{l i}=(1-\phi) \Pi^{\circ}, \pi_{t a}=\phi \Pi^{\circ}$.

Through Equation (16), it is easy to see that the commission price decreases with the channel's optimal demand under the discount quantity contracts. To achieve channel coordination, the tourism supply chain is motivated to decrease the commission price, which leads to the decrease in the price of package tours and attracts more tourists. However, when tourists arrive in the destinations, local operators will take various actions to force tourist to consume excessive optional tours (Zhang et al, 2009a). According to the definition of OLC, OLC appears if $w \leq c_{l}$. By substituting $q^{\circ}$ into Equation (16), we can obtain $\left(w-c_{l}\right)$ as:

$$
w-c_{l}=\frac{\phi c_{e}}{2}-\frac{\phi(1+\alpha \lambda)(\alpha \theta+\nu)}{2}+\frac{\alpha \theta+\nu}{2}+\frac{c_{e}}{2(1+\alpha \lambda)}-c_{l}-c_{l}
$$

Equation (17) shows under what condition OLC occurs.

Proposition 4. If the follow condition holds:

$$
\frac{(1+\alpha \lambda)\left(\alpha \theta+v-2\left(c_{t}+c_{l}\right)\right)+c_{e}}{(1+\alpha \lambda)(\alpha \theta+v)-c_{e}} \leq \phi \leq \frac{1}{2+\alpha \lambda},
$$

then the local operator's commission price $(w)$ is no greater than the cost of providing tour service $\left(c_{l}\right)$ under quantity discount contract, that is, OLC occurs. (The proof is straightforward and omitted.)

Proposition 4 indicates that quantity discount contracts can provide conditions for the creation of OLC. Thus, we can conclude that short-term coordination might be a driver of OLC. Proposition 4 presents the conditions of OLC in terms of $\phi$. The following corollary shows that the ratio of optional tours is a fundamental condition of OLC.

Corollary 1.

$$
\text { If } \alpha \theta+v+2 c_{e}+\frac{c_{e}}{1+\alpha \lambda}>2\left(c_{t}+c_{i}\right)(2+\alpha \lambda),
$$

OLC does not appear.

By defining $\chi(\alpha)$ as:

$$
\chi(\alpha)=\alpha \theta+v-2\left(c_{t}+c_{l}\right)(2+\alpha \lambda)+2 c_{e}+\frac{c_{e}}{1+\alpha \lambda},
$$


then $\chi(\alpha)$ has the following properties:

(a) if $\theta \geq \lambda\left(2 c_{l}+2 c_{l}+c_{e}\right)$, then $\chi(\alpha)$ increases with $\alpha$;

(b) if $2 \lambda\left(c_{l}+c_{l}\right)<\theta<\lambda\left(2 c_{l}+2 c_{l}+c_{e}\right)$, then $\chi(\alpha)$ first decreases and then increases with $\alpha$;

(c) if $\theta \leq 2 \lambda\left(c_{l}+c_{t}\right)$, then $\chi(\alpha)$ decreases with $\alpha$.

Since $\chi(0)>0, \chi(\alpha)$ is greater than zero for $\alpha>0$ in case (a). In case (b), we denote that the global minimum $\chi(\alpha)$ by $\widetilde{\alpha}$. If $\widetilde{\alpha}<0$ or $\chi(\widetilde{\alpha})>0, \chi(\alpha)$ is also greater than zero for $\alpha>0$. If $\widetilde{\alpha}>0$ and $\chi(\widetilde{\alpha})<0$, then there is a range of $\alpha$ in which $\chi(\alpha)<0$. In case (c), $\chi(\alpha)$ has only one zero point and OLC cannot appear when $\alpha$ is less than the zero. The above analysis reveals that a large proportion of optional tours are the fundamental conditions of OLC.

As a conclusion of coordination analysis, we provide the following insight.

Insight 2. OLC is economically effective for the channel from the perspective of coordination. To some content, coordination might be a driver of OLC. More importantly, a large proportion of optional tours are fundamental conditions of OLC.

\section{Tax effects}

A few empirical studies point out that zero or minus commission does more harm than good to the tourism industry (Zhang et al, 2009a, 2009b). First, zero or minus commission makes tourists suffer considerable psychological and financial costs. Second, mass tourist arrivals caused by zero or minus commission result in excessive deterioration in environmental quality in destinations. Considering the harmful effects of zero or minus commission, we present a further discussion on how to curb OLC.

Since zero or minus commission has led to serious tourist dissatisfaction, tourists begin to exhibit some aversion to optional tours. Hence, we study the tourism supply chain with $\theta<0$ here. Motivated by taxation of tourism activities (Palmer and Riera, 2003; Gago et al, 2009), a tax aimed at optional tours is introduced into the tourism supply chain. In applying the tax we intend to achieve two effects: adjusting tourist arrivals and curbing OLC. These two effects will be verified in the subsequent analysis.

Under taxation, the local operator needs to pay tax rop for sale of the optional tours where $r$ is the tax rate. The local operator's and tour operator's tax adjusted profits are as follows:

$$
\begin{aligned}
& \pi_{l o}=A(v-p+\theta \alpha)\left(w-c_{l}+\lambda\left(\alpha p(1-r)-c_{l o}\right)\right), \\
& \pi_{t s}=A(v-p+\theta \alpha)\left(p-w-c_{t}\right) .
\end{aligned}
$$

The condition to guarantee that the equilibrium demand $\left(q^{* *}\right)$ is greater than zero is $0<\alpha<\widetilde{\alpha}_{1}$, where:

$$
\widetilde{\alpha}_{1}=-\frac{\theta+\lambda \nu(1-r)+\sqrt{4 \theta \lambda(1-r)\left(c_{e}-v\right)+(\theta+\lambda(1-r) v)^{2}}}{2 \theta \lambda(1-r)} .
$$


The above model can be solved by backwards induction producing an equilibrium commission price $\left(w^{* *}\right)$ as:

$$
w^{* *}=\frac{c_{e}+\alpha \theta+v}{2+\alpha \lambda(1-r)}-c_{\imath} .
$$

From Equation (23) we see that the commission price is increasing with the ratio of optional tours when $\theta>\lambda(1-r)\left(c_{e}+v\right) / 2$. Comparing with the case without $\operatorname{tax}\left(\theta>\lambda\left(c_{e}+v\right) / 2\right)$, the local tour operator is more likely to increase the commission price by increasing the ratio of optional tours. The demand function $\left(q^{* *}\right)$ is:

$$
q^{* *}=A \frac{(\alpha \theta+v)(\alpha \lambda(1-r)+1)-c_{e}}{2(2+\alpha \lambda(1-r))} .
$$

Since $\partial q^{* *} / \partial r<0$, the equilibrium demand decreases with tax rate. Thus, the policymaker can control the arrivals of tourists by adjusting the tax rate in the equilibrium scenario. The two players' equilibrium profits are:

$$
\begin{aligned}
& \pi_{l \prime}^{* *}=A \frac{\left((\alpha \theta+v)(\alpha \lambda(1-r)+1)-c_{e}\right)^{2}}{4(2+\alpha \lambda(1-r))}, \\
& \pi_{t \prime}^{* *}=A \frac{\left((\alpha \theta+v)(\alpha \lambda(1-r)+1)-c_{e}\right)^{2}}{4(2+\alpha \lambda(1-r))^{2}} .
\end{aligned}
$$

We discuss the relationship between the ratio of optional tours and two players' equilibrium profits after tax. Then the following proposition is concluded.

Proposition 5. If tourists in the source market are optional tour aversion $(\theta<0)$, let

$$
\widetilde{\alpha}_{2}=-\left(9 \theta+\lambda \nu(1-r)+\sqrt{\left.(9 \theta-\lambda \nu(1-r))^{2}-12 \theta\left(4 \theta+\lambda(1-r) c_{e}\right)\right) /(6 \theta \lambda(1-r))}\right.
$$

and

$$
\left.\widetilde{\alpha}_{3}=-\left(2 \theta+\sqrt{\theta\left(2 \theta-\lambda(1-r)\left(c_{e}+v\right)\right.}\right)\right) /(\theta \lambda(1-r)),
$$

then the following properties hold.

(a) If $\theta \leq-\lambda\left(c_{e}+3 v\right)(1-r) / 4$, then the local operator's equilibrium profit after $\operatorname{tax}\left(\pi_{l,}^{* *}\right)$ decreases with the proportion $(\alpha)$ in $\left(0, \widetilde{\alpha}_{1}\right)$.

(b) If $-\lambda\left(c_{e}+3 v\right)(1-r) / 4<\theta<0$ and $v>\max \left\{c_{e},\left(\theta+2 \sqrt{\left.-\lambda \theta c_{e}(1-r)\right)} /((1-r) \lambda)\right\}\right.$, then the local operator's equilibrium profit after $\operatorname{tax}\left(\pi_{l 0}^{* *}\right)$ increases with the proportion in $\left(0, \widetilde{\alpha}_{2}\right]$ and decreases in $\left[\widetilde{\alpha}_{2}, \widetilde{\alpha}_{1}\right)$. 
(c) If $\theta \leq-\lambda(1-r)\left(c_{e}+v\right) / 2$, then the tour operator's equilibrium profit after tax $\left(\pi_{t 0}^{* *}\right)$ decreases with the proportion in $\left(0, \widetilde{\alpha}_{1}\right)$.

(d) If $-\lambda(1-r)\left(c_{e}+v\right) / 2<\theta<0$ and $v>\max \left\{c_{e},\left(\theta+2 \sqrt{\left.-\lambda \theta c_{e}(1-r)\right)} /((1-r) \lambda)\right\}\right.$ then the tour operator's equilibrium profit after $\operatorname{tax}\left(\pi_{t, 0}^{* *}\right)$ increases with the proportion in $\left(0, \widetilde{\alpha}_{3}\right]$ and decreases in $\left[\widetilde{\alpha}_{3}, \widetilde{\alpha}_{1}\right)$. (The proof of Proposition 5 is similar to that of Proposition 2, and therefore omitted.)

From Equation (21) we derive the channel's profit after tax:

$$
\Pi(p)=A(v-p+\theta \alpha)\left(p-c_{l}-c_{l}+\lambda\left(\alpha p(1-r)-c_{l o}\right)\right) .
$$

Then the channel's optimal product price is:

$$
p^{\circ 0}=\frac{\alpha \theta+v}{2}+\frac{c_{e}}{2(1+\alpha \lambda(1-r))},
$$

which is increasing with the ratio of optional tours when $\theta>\lambda c_{e}(1-r) /$ $(1+\alpha \lambda(1-r))^{2}$; otherwise, $p^{\circ 0}$ is decreasing with $\alpha$. Comparing with the case without $\operatorname{tax}\left(\theta>\lambda_{c} /(1+\alpha \lambda)^{2}\right)$, we see that the optimal product price is more likely to increase with the ratio of optional tours. The optimal demand is:

$$
q^{\circ}=A\left(\frac{\alpha \theta+v}{2}-\frac{c_{e}}{2(1+\alpha \lambda(1-r))}\right)
$$

Since $\partial q^{\circ} / \partial r<0$, tourist arrivals can also be adjusted by changing the tax rate in the coordination scenario. The optimal profit is:

$$
\Pi^{\circ \circ}=A \frac{\left((\alpha \theta+v)(1+\alpha \lambda(1-r))-c_{e}\right)^{2}}{4(1+\alpha \lambda(1-r))} .
$$

Similarly, we also employ quantity discount contracts to achieve channel coordination under the tax mechanism.

Proposition 6. If the following condition holds:

$$
\frac{1+\alpha \lambda(1-r)}{(2+\alpha \lambda(1-r))^{2}} \leq \phi \leq \frac{1}{2+\alpha \lambda(1-r)}
$$

and then the tourism supply chain can be coordinated under quantity discount contracts:

$$
\widetilde{w}(q)=-c_{t}+\phi c_{e}+(1-\phi(1+\alpha \lambda(1-r)))(v+\theta \alpha-q / A) .
$$

And $\pi_{t o}=\phi \Pi^{\circ \circ}, \pi_{l o}=(1-\phi) \Pi^{\circ \circ}$. (The proof is straightforward, thus omitted.) Observing Equations (16) and (32), we see that for identical increase in 
optimal demand $\Delta q$, the decrease in commission price without tax is $\Delta q \phi(1+\alpha \lambda) / A$ and the decrease with tax is $\Delta q \phi(1+\alpha \lambda(1-r)) / A$. Obviously, tax can reduce the effect of the discount on commission price. Intuitively, if the tax rate is sufficiently large then $\tilde{w} \leq c_{l}$ might be curbed. Corollary 2 reveals the condition.

Corollary 2. When the tax rate meets the following condition:

$$
\underline{r}<r<\min \{1, \bar{r}\}
$$

and then OLC can be curbed. Here:

$$
\begin{aligned}
& \underline{r}=1-\left(\alpha \theta+2 \lambda c_{l n}+v-4\left(c_{t}+c_{l}\right)+\sqrt{8 c_{e}\left(c_{l}+c_{l}\right)+\left(\alpha \theta+2 \lambda c_{l n}+v\right)^{2}}\right) /\left(4 \alpha \lambda\left(c_{t}+c_{l}\right)\right) \\
& \bar{r}=1-\left(\alpha \theta+2 \lambda c_{l n}+v-4\left(c_{l}+c_{l}\right)-\sqrt{8 c_{e}\left(c_{l}+c_{l}\right)+\left(\alpha \theta+2 \lambda c_{l n}+v\right)^{2}}\right) /\left(4 \alpha \lambda\left(c_{t}+c_{l}\right)\right) .
\end{aligned}
$$

So far, the effects of the tax, adjusting tourist arrivals and curbing OLC, have been both verified in the previous analysis. In addition, comparing Proposition 5 with Proposition 2, we can find that the form of each player's profit function is not distorted by the tax, but the positions of extreme points change with tax rate. Thus, policymakers can affect the two players' decision making by changing the tax rate in the equilibrium scenario. In summary we provide the following insight.

Insight 3. Tourist arrivals can be adjusted and OLC can be curbed by setting proper tax rate. Furthermore, each player's equilibrium profit function is not distorted by tax, but the positions of extreme points change with the tax rate.

\section{Numerical examples}

In this section, we provide some numerical examples to illustrate the corresponding conclusions derived in the previous sections. The basic parameters in these examples are:

$$
A=1, c_{i}=2, c_{l}=3, c_{l \prime}=2.5, v=15, \lambda=0.6
$$

\section{Equilibrium profits without tax}

First, we present instances for illustrating the conclusions in equilibrium profits without tax. In the first instance with $\theta=5$ (Proposition 1), both the local operator's equilibrium profit $\left(\pi_{l n}^{*}\right)$ and the tour operator's equilibrium profit $\left(\pi_{t \prime}^{*}\right)$ increase with the ratio of optional tours $(\alpha)$ due to $\theta=5$. The two players' equilibrium profit functions are visualized in Figure 1. Obviously, both $\left(\pi_{l o}^{*}\right)$ and $\left(\pi_{t}^{*}\right)$ increase with $\alpha$.

In the second instance with $\theta=-8$ (Figure 2), due to $\theta<-\lambda\left(c_{e}+3 v\right) / 4$ (property (a) and (c) in Proposition 2), tourists in the source market are sufficiently averse to optional tours. Thus, both the local operator's and the tour operator's equilibrium profits $\left(\pi_{l n}^{*}, \pi_{t o}^{*}\right)$ decrease with the proportion in $(0,1.438)$. 


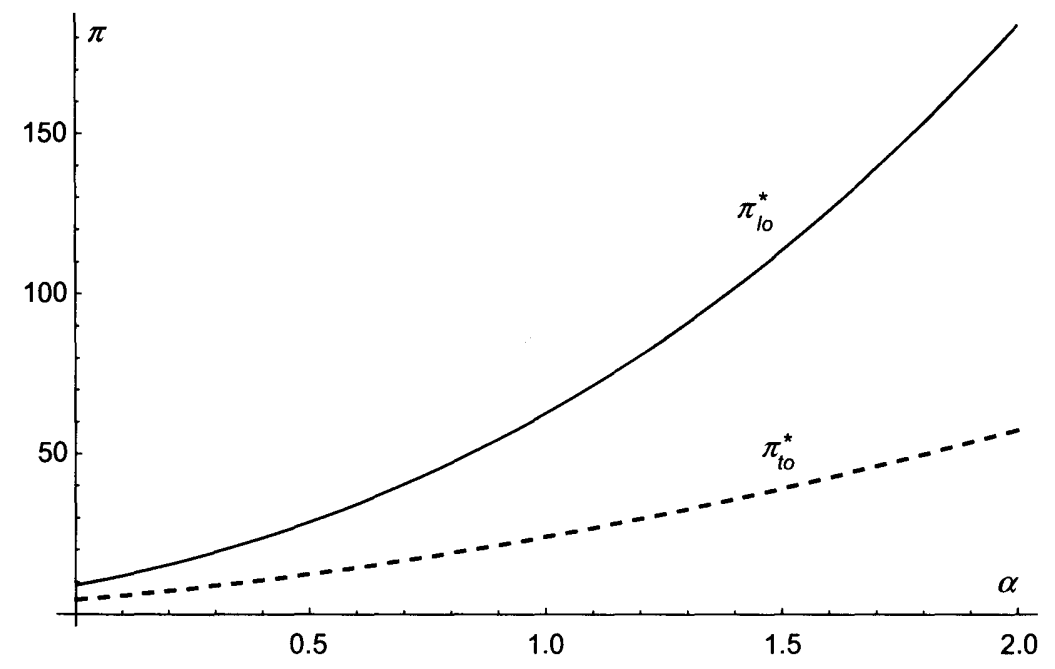

Figure 1. Local operator's and tour operator's equilibrium profits with $\theta=5$.

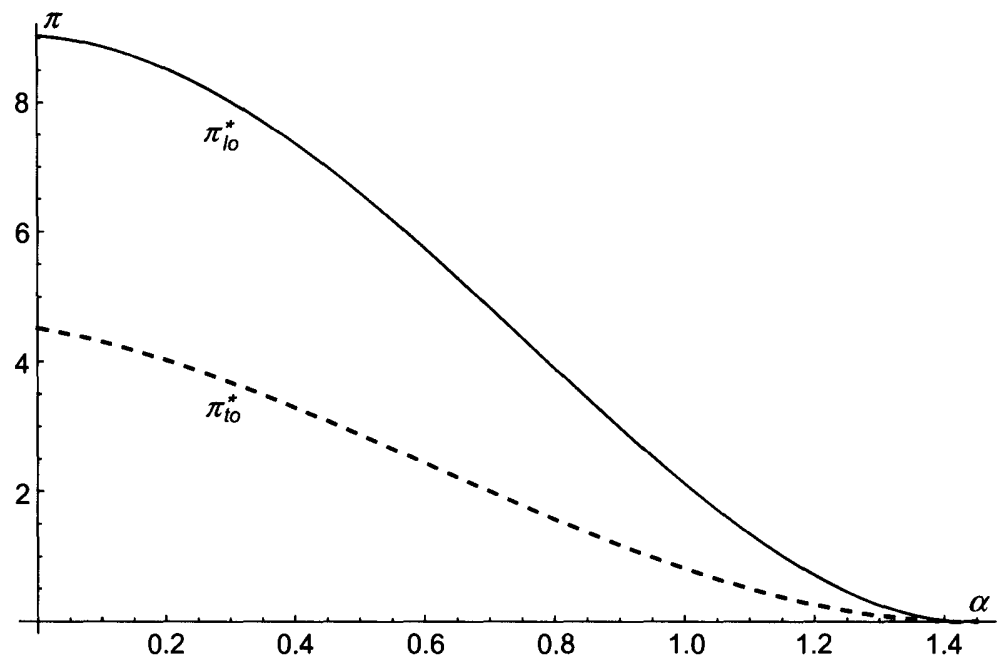

Figure 2. Local operator's and tour operator's equilibrium profits with $\theta=-8$.

In the third case with $\theta=-3$ (Figure 3), tourists in the source market are only slightly averse to optional tours. According to property (b) in Proposition 2 , the local operator's equilibrium profit $\left(\pi_{l o}^{*}\right)$ increases with the proportion in $(0,1.268]$ and then decreases in $[1.268,4.405]$. Correspondingly, the tour operator's equilibrium profit $\left(\pi_{t 0}^{*}\right)$ increases with the proportion in $(0,0.8501$ and then decreases in $[0.850,4.405]$. If the original proportion in the contract 


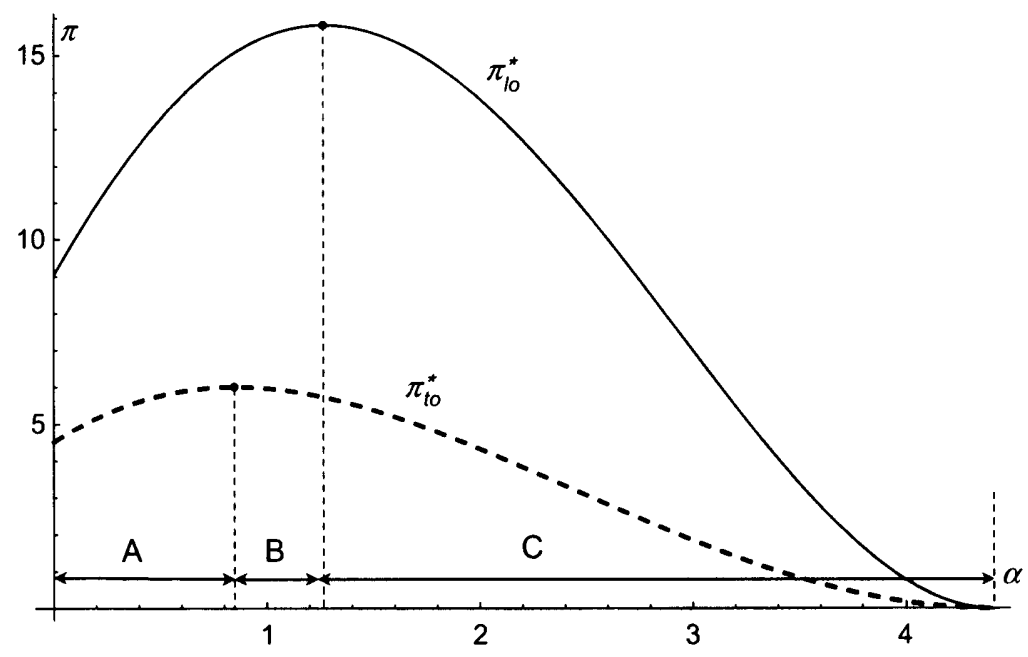

Figure 3. Local operator's and tour operator's equilibrium profits with $\theta=-3$.

lies in interval A $((0,0.850])$, both players are Pareto benefited by increasing the proportion. If the original proportion lies in interval $\mathrm{B}((0.850,1.268])$, an increase in proportion benefits the local operator and hurts the tour operator. As a result, whether to change the proportion might depend on each player's bargaining power. Specifically, when the local operator has more bargaining power, the proportion is likely to increase; otherwise, the proportion is likely not to change or to decrease. In interval $\mathrm{C}([1.268,4.405])$, both players' profits decrease with the proportion.

\section{Optional tours in $O L C$}

We now analyse the role of optional tours in OLC numerically. Figure 4 visualizes $\chi(\alpha)$ under different cases in which tourists' attitudes in optional tours $(\theta)$ change (Corollary 1). In the case with $(\theta=7)\left(2 \lambda\left(c_{l}+c_{l}\right)<\theta<2 \lambda\left(c_{l}+c_{l}\right)+\lambda_{e}\right)$, $\chi(\alpha)$ first decreases in $[0,1.625]$ and then increases with the proportion $(\widetilde{\alpha}=1.625)$. Since $\chi(\widetilde{\alpha})>0$, OLC does not occur in this case either. However, in the above two cases, tourists in the source market have a high level of preference for optional tours, which is not likely to appear in practice. In particular, owing to the negative effects of OLC, tourists are more likely to have low-level preference or aversion to optional tours $\left(\theta \leq 2 \lambda\left(c_{l}+c_{l}\right)\right)$. The $\theta=1$ and $\theta=-1$ curves correspond to a low-level preference case and aversion case, respectively. Both decrease with the proportion and if the proportion exceeds the zero points $(1.615,0)$ and $(2.165,0)$, OLC appears (Equation (18) holds). Conversely, if the proportion is relatively small (for example, $\alpha$ is less than 1.615 in the case with $\theta=-1$ ), OLC does not occur. The zero point of the $\theta=-8$ curve is relatively small ( $\alpha=0.876$ ); however, this is an extreme case in which tourists are sufficiently averse to optional tours. Generally, this case is not common in practice. Based on this numerical instance, we conclude that OLC is not likely to occur if the ratio of optional tours is relatively small in practice. In other words, a large proportion of optional tours are fundamental conditions of OLC. 


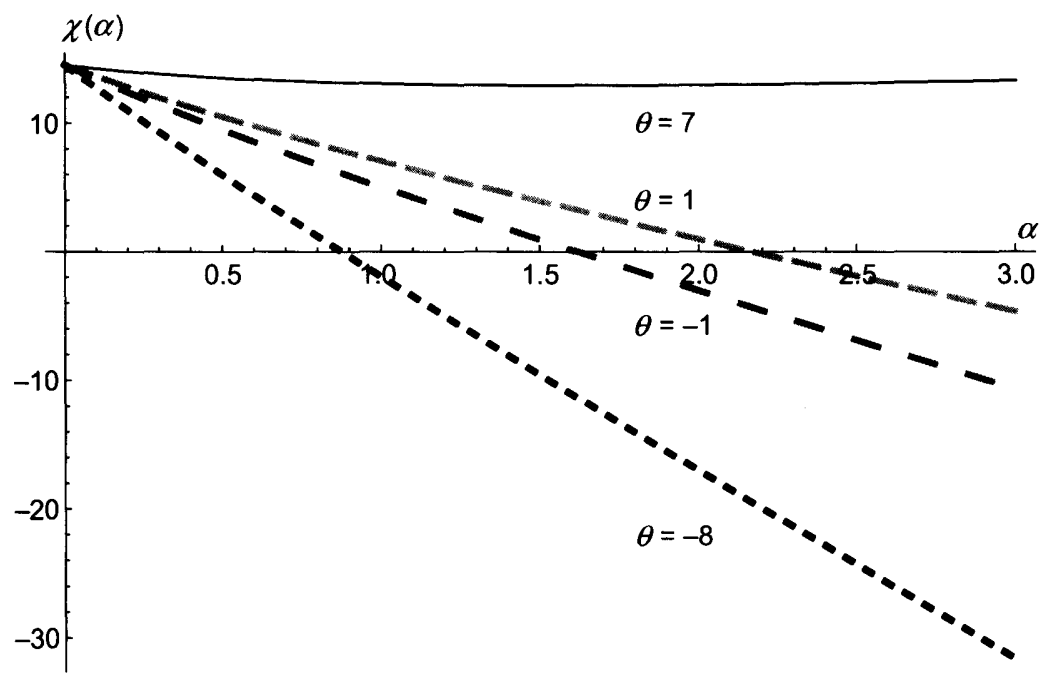

Figure 4. $\chi(\alpha)$ under some cases with different $\theta$.

\section{Tax effects}

Finally, we provide an instance with $\theta=-1$ for illustrating tax effects on curbing OLC. As mentioned in Corollary 2, the tax rate $r$ should meet $\underline{r}<r$ $<\min \{1, \bar{r}\}$ to curb OLC. In Figure $5, \underline{r}$ and $\bar{r}$ are visualized by the dashed and dot-dashed curves, respectively. The points in the shadowed area between $r=$ 1 and $\underline{r}$ correspond to the feasible tax rates. Obviously, $\underline{r}$ concavely increases with the proportion. Since the ratio of optional tours cannot be extremely large in practice, we select a sample point $(2,22 \%)$ from $\underline{r}$ to show the effects of tax. When the ratio of optional tours $(\alpha)$ is 2 and tax rate is $10 \%$, the quantity discount contract for coordination is $w=6.0625-10.27 \phi, 0.219 \leq \phi \leq 0.324$, (Proposition 3). The condition of OLC is $0.298 \leq \phi \leq 0.324$ (Proposition 4), thus, OLC might occur when tax rate is $10 \%$. However, if $\alpha$ is 2 and tax rate is $25 \%$, then the contract is $w=6.2105-9.1 \phi, 0.226 \leq \phi \leq 0.344$. The condition of OLC is $\phi \geq 0.3528$. Obviously, there does not exist any real value $\phi$ that makes OLC hold; that is, OLC is curbed with $r=25 \%$.

In addition, we analyse the effects of tax on equilibrium profits numerically. Figure 6 visualizes each player's profit function $\left(\pi_{l o}^{* *}(r), \pi_{t r}^{* *}(r)\right)$ under two different tax rates $(r=17 \%$ and 30\%). Comparing with the curves in Figure 3 (special case with $r=0$ ), we can find that the form of each player's equilibrium profit function is not distorted by tax. Yet, the positions of extreme points change with the tax rate. It is easy to calculate that $\partial \widetilde{\alpha}_{2} / \partial r<0, \partial \widetilde{\alpha}_{3} / \partial r<0$, in this instance, thus extreme points move left with the increase in the tax rate. Furthermore, the policymaker can affect the local operator's and the tour operator's decision making by changing tax rate. For example, if the local government intends to curb the increase in the proportion $\alpha$ (the increase in $\alpha$ might help the growth of OLC, see Insight 2), an effective way is to increase the tax rate. Then the length of interval $\left(A^{\prime}, A^{\prime \prime}\right)$, in which the two players are motivated to increase the proportion, decreases with the tax rate. Thus, the original proportion in the contract is more likely to fall in other intervals in which the proportion does not change or decrease. 


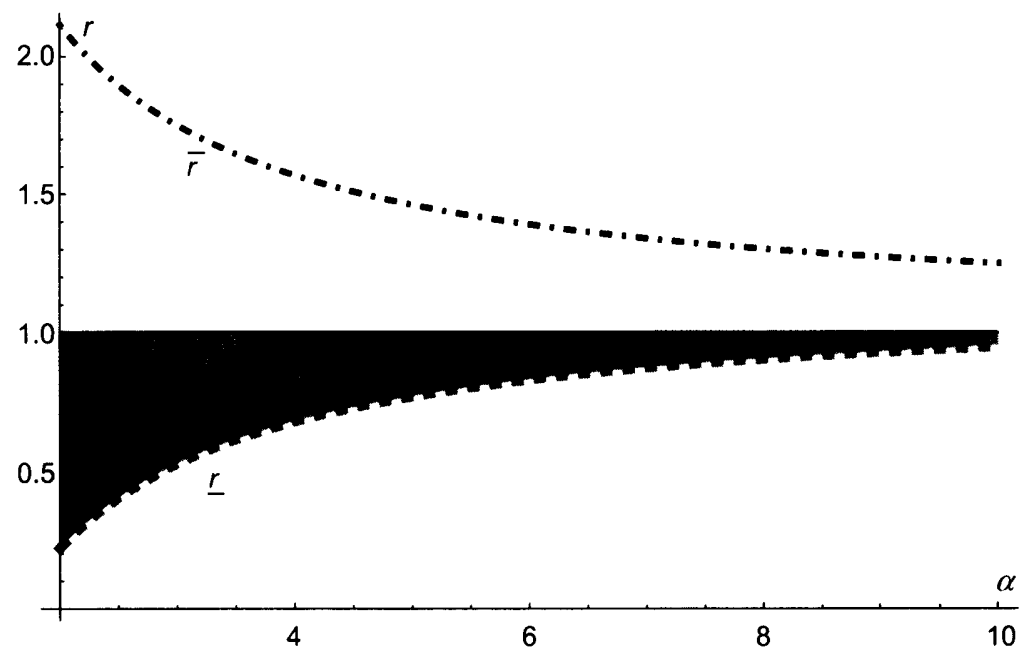

Figure 5. The range of tax rates that curb ZMC.

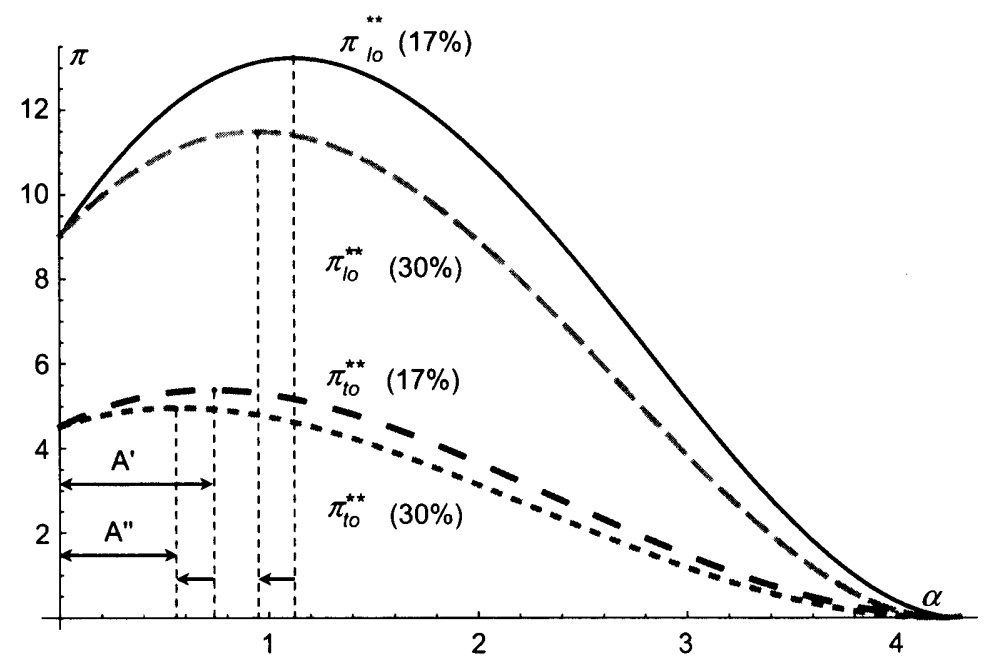

Figure 6. Local operator's and tour operator's equilibrium profits with different tax rates.

\section{Extensions}

To ease the technical difficulties we consider a simple tourism supply chain model in the previous analysis. The simplified model may not represent reality. In order to verify the effectiveness of our model and findings, we provide further discussion about the findings as they relate to the following extensions to our model: multiple operators in destination and source market, multi-attribute utility of the tourists as well as information asymmetry. 


\section{Multiple operators in both destination and source market}

In practice, there are many operators competing in both the destination and the source market. A possible extension of our model is to incorporate more players into the tourism supply chain, for example, a model that incorporates a tour operator in source market and $n(\geq 1)$ local operators in the destination. A two stage game can be used to characterize the price competition (it is similar with the model in Guo et al (2013) which considers one third-party website and multi-hotels). In the first stage, the $n$ local operators compete on the commission price to achieve proper allocation of tourists from the tour operator in the source market. After each local operator's commission is announced, the tour operator decides the price of the package tours and the allocation to each local operator. By backwards induction we can solve each operator's equilibrium decision and profit. For the local operators, since the tourists' attitude in optional tours and the ratio of optional tours also affect their equilibrium profits, Proposition 1 and 2 may remain valid under some conditions. Moreover, the commission competition among the local operators results in even lower commission price (local operators will decrease commission price further to achieve competitive advantage on the allocation of tourists.), which implies that the OLC is more likely to occur in the multiple-local-tour-operator case comparing with the original model. Zhang et al (2009a) point out fierce competition among operators to enter into Chinese outbound market. In addition, quantity discount contracts may help achieve the coordination of the tourism supply chain again, which corresponds to Proposition 3. (For example, Dong et al (2012) use a quantity discount contract to coordinate the pricing competition among three players.) Similarly, in the coordinated scenario, each local operator is motivated to lower the commission further, which induces the OLC again. As a result, the tax is still an option for curbing OLC and the tax rate could be higher comparing with the original model; referring to Proposition 4,5 and 6 . By following the same idea, we can consider the multiple-touroperator case, even the multiple-tour-operator and multiple-local-operator case as a future research direction.

\section{Multi-attribute utility function}

For the sake of tractability, it is assumed that the basic utility from consuming package tours is homogeneous for each tourist. However, it is common to see that tourists have different utilities for consuming even homogenous products. We can incorporate this fact into the utility function, that is, Equation (1) can be rewritten as:

$$
U(\eta, \gamma)=\eta Q_{p}+\alpha \theta-p-\gamma
$$

where $Q_{p}$ is the quality of package tours and $\eta$ is tourists' attitude in the package tours.

For convenience, it is also assumed that $\eta$ uniformly distributes in an interval. As a result, the demand for package tours is derived from the participation constraint $U(\eta, \gamma) \geq 0$ on a two-dimension plane. Even with the simplified assumption on the distribution of $\eta$, there may be great analytical 
difficulties to derive the closed form solution. An alternative way is that study tour operators' decisions based on some numerical examples. In particular, the interesting question is how $Q_{p}$ affects local operators' equilibrium profits and the connection between the quality of predesigned tours and OLC, which remains open for future research.

\section{Information asymmetry}

A basic assumption in our model is that tourists and operators share symmetric information. However, it is also common to see information asymmetry in reality. Our future research will extend to the pricing decisions and coordination mechanism in the asymmetric information situation. In particular, the local operators might benefit from information hiding. In that case, it is necessary to analyse the value of information and design a contract to reveal the hiding information based on a principal-agent model.

\section{Conclusion}

In this paper, we provided analysis of a tourism supply chain with optional tours. At first, we derived the local operator's and the tour operator's equilibrium pricing decisions and profit functions. Based on the analysis of each player's equilibrium decision and profit, we provided some insights into how to adjust the makeup of optional tours in the equilibrium scenario. Generally speaking, the proportion of optional tours depends on tourists' attitudes in optional tours in the source market. Specifically, if tourists have positive preference for optional tours, the increase in the proportion benefits both of two players. If tourists are sufficiently averse to optional tours, then the increase in the proportion hurts the two players.

We also gave coordination analysis to study OLC. Specifically, we employed quantity discount contracts under which the commission that the local operator charged is discounted according to the quantity of products sold. Further analysis of the contracts identifies the conditions under which OLC appears. This finding indicates that OLC is economically effective from the perspective of coordination. In other words, coordination might be a driver of OLC to some extent. In addition, we analysed the relationship between OLC and optional tours, which shows that OLC is not likely to occur when the ratio of optional tours is relatively small. Thus, a large ratio of optional tours provides fundamental conditions for OLC.

Considering the adverse effects of zero or minus commission in Chinese tourism industry, we presented a taxation structure to limit OLC. A tax mechanism aimed at optional tours is introduced into the tourism supply chain. The tax helps achieve two goals: adjusting tourists' arrivals and curbing OLC. Our analysis verified that these two goals can be both reached by establishing a proper tax rate. Moreover, each player's profit function is not distorted by the tax, but the positions of extreme points change with tax rate. Thus, local governments can affect the two players' decision making by changing tax rate. The discussion on tax might provide some theoretical support for local government intervention in destinations. 


\section{References}

Dong, J., Zhang, J., Liang, L., and Guo, Q. (2011), 'Cooperation pattern and coordination mechanism between Hong Kong Disneyland and tour operator', Journal of China Tourism Research, Vol 7, No 3, pp 310-325.

Dong, J., Shi, Y., Liang, L., and Wu, H. (2012), 'Comparative analysis of underdeveloped tourism destinations' choice of cooperation modes: a tourism supply chain model', Tourism Economics, Vol 18, No 6, pp 1377-1399.

Enoch, Y. (1996), 'Contents of tour packages: a cross-cultural comparison', Annals of Tourism Research, Vol 23, No 3, pp 599-616.

Gago, A., Labandeira, X., Picos, F., and Rodríguez, M. (2009), 'Specific and general taxation of tourism activities. Evidence from Spain', Tourism Management, Vol 30, No 3, pp 381-392.

Guo, X., and He, L. (2012), 'Tourism supply chain coordination: the cooperation between tourism hotel and tour operator', Tourism Economics, Vol 18, No 6, pp 1361-1376.

Guo, X., Ling, L., Dong, Y., and Liang, L. (2013), 'Cooperation contract in tourism supply chains: the optimal pricing strategy of hotels for cooperative third party strategic websites', Annals of Tourism Research, Vol 41, No, pp 20-41.

Huang, G.Q., Chen, W., Song, H., and Zhang, X. (2010a), 'Game-theoretic study of the dynamics of tourism supply chains for package holidays under quantity competition', Tourism Economics, Vol 16, No 1, pp 197-216.

Huang, G.Q., Song, H., and Zhang, X. (2010b), 'A comparative analysis of quantity and price competitions in tourism supply chain networks for package holidays', Service Industries Journal, Vol 30, No 10, pp 1593-1606.

Huang, Y., Song, H., Huang, G.Q., and Lou, J. (2012), 'A comparative study of tourism supply chains with quantity competition', Journal of Travel Research, Vol 51, No 6, pp 717-729.

Lee, S.K., and Jang, S. (2013), 'Asymmetry of price competition in the lodging market', Journal of Travel Research, Vol 52, No 1, pp 56-67.

Ling, L., Guo, X., and He, L. (2012), 'Optimal pricing strategy of hotel for long-term stay', International Journal of Services Technology and Management, Vol 17, No 1, pp 72-86.

Ling, L., Guo, X., and Liang, L. (2011), 'Optimal pricing strategy of a small or medium-sized hotel in cooperation with a web site', Journal of China Tourism Research, Vol 7, No 1, pp 20-41.

Mak, A.H.N., Wong, K.K.F., and Chang, R.C.Y. (2011), 'Critical issues affecting the service quality and professionalism of the tour guides in Hong Kong and Macau', Tourism Management, Vol 32, No 6, pp 1442-1452.

Palmer, T., and Riera, A. (2003), "Tourism and environmental taxes. With special reference to the "Balearic ecotax", Tourism Management, Vol 24, No 6, pp 665-674.

Schiff, A., and Becken, S. (2011), 'Demand elasticity estimates for New Zealand tourism', Tourism Management, Vol 32, No 3, pp 564-575.

Song, H., Yang, S., and Huang, G.Q. (2009), 'Price interactions between theme park and tour operator', Tourism Economics, Vol 15, No 4, pp 813-824.

Wang, K.-C., Hsieh, A.-T., and Huan, T.-C. (2000), 'Critical service features in group package tour: an exploratory research', Tourism Management, Vol 21, No 2, pp 177-189.

Wang, K.-C., Jao, P.-C., Chan, H.-C., and Chung, C.-H. (2010), 'Group package tour leader's intrinsic risks', Annals of Tourism Research, Vol 37, No 1, pp 154-179.

Yang, S., Huang, G.Q., Song, H., and Liang, L. (2009), 'Game-theoretic approach to competition dynamics in tourism supply chains', Journal of Travel Research, Vol 47, No 4, pp 425-439.

Zhang, H.Q., Heung, V.C.S., and Yan, Y.Q. (2009a), 'Play or not to play - an analysis of the mechanism of the zero-commission Chinese outbound tours through a game theory approach', Tourism Management, Vol 30, No 3, pp 366-371.

Zhang, H.Q., Yan, Y.Q., and Li, Y. (2009b), 'Understanding the mechanism behind the zerocommission Chinese outbound package tours: evidence from case studies', International Journal of Contemporary Hospitality Management, Vol 21, No 21, pp 734-751.

Zhang, Y., and Murphy, P. (2009), 'Supply chain considerations in marketing underdeveloped regional destinations: a case study of Chinese tourism to the Goldfields region of Victoria', Tourism Management, Vol 30, No 2, pp 278-287. 


\section{Appendix: Proofs}

Besides the parameters $\hat{\alpha}_{1}, \hat{\alpha}_{2}$ and $\hat{\alpha}_{3}$ in the previous sections, we conclude the other three related parameters in this section as follows:

$$
\begin{aligned}
& \hat{\alpha}_{4}=-\frac{\theta+\lambda v-\sqrt{(\theta-\lambda v)^{2}+4 \theta \lambda c_{e}}}{2 \theta \lambda}, \\
& \hat{\alpha}_{5}=-\frac{9 \theta+\lambda v-\sqrt{(9 \theta-\lambda v)^{2}-12 \theta\left(4 \theta+\lambda_{i}\right)}}{6 \theta \lambda}, \\
& \hat{\alpha}_{6}=-\frac{2 \theta-\sqrt{\theta\left(2 \theta-\lambda\left(c_{c}+v\right)\right)}}{\theta \lambda} .
\end{aligned}
$$

\section{Proof of Proposition 1}

In the cases with $\theta>0$, due to $v>c_{t}, \hat{\alpha}_{1}<\hat{\alpha}_{4}<0$. To guarantee that $q^{*}>0, \alpha$ should be greater than zero. Taking the derivative of $\pi_{l,}^{*}$ with respect to $\alpha$, we can find that $\partial \pi_{l l}^{*} / \partial \alpha>0$. Similarly, take the derivative of $\pi_{t \prime}^{*}$ with respect to $\alpha$, we can get $\partial \pi_{t \prime}^{*} / \partial \alpha>0$. Thus, both the local operator's equilibrium profit and the tour operator's equilibrium profit increase with $\alpha$.

\section{Proof of Proposition 2}

In the cases with $\theta<0$, to guarantee that that $q^{*}>0$, $\alpha$ should satisfy $0<\alpha<\hat{\alpha}_{1}$. Solving $\partial \pi_{t /}^{*} / \partial \alpha=0$ we can obtain the three roots $\hat{\alpha}_{2}, \hat{\alpha}_{4}$ and $\hat{\alpha}_{5}$. Then we discuss each player's profit function in different cases based on the relationships of $\hat{\alpha}_{2}, \hat{\alpha}_{4}$ and $\hat{\alpha}_{5}$. The local operator's profit function:

(a) If $\theta \leq-\lambda\left(c_{e}+3 v\right) / 4$, then $\hat{\alpha}_{s}<\hat{\alpha}_{2} \leq 0$, thus $\pi_{l,}^{*}$ decreases with $\alpha$ for $0<\alpha<\hat{\alpha}_{1}$.

(b) If $-\lambda\left(c_{e}+3 v\right) / 4<\theta<0$, then $\hat{\alpha}_{5} \leq 0<\hat{\alpha}_{2}$. Combining with $\hat{\alpha}_{1}$ and $\hat{\alpha}_{4}$, the relationships of the parameters might follow two cases: (b1) $\hat{\alpha}_{5} \leq 0<\hat{\alpha}_{2}<\hat{\alpha}_{1}$, (b2) $\hat{\alpha}_{5} \leq 0<\hat{\alpha}_{1}<\hat{\alpha}_{2}$.

Case (b1) holds if and only if $v>\max \left\{0,\left(\theta+2 \sqrt{-\theta_{c}}\right) / \lambda\right\}$, and in case (b1) $\pi_{l n}^{*}$ decreases with $\alpha$ in $\left[\hat{\alpha}_{2}, \hat{\alpha}_{1}\right]$ and increases in $\left(0, \hat{\alpha}_{2}\right]$. It is not difficult to verify that case (b2) cannot hold, thus omitted.

The tour operator's profit:

From Equation (A1) we can find that $\hat{\alpha}_{6}<0$. However, for $\hat{\alpha}_{3}$, if $\theta \leq-\lambda\left(c_{e}+v\right) /$ 2 , then $\hat{\alpha}_{3} \leq 0$; else if $-\lambda\left(c_{\varepsilon}+v\right) / 2<\theta<0, \hat{\alpha}_{3}>0$.

(c) If $\theta \leq-\lambda\left(c_{e}+v\right) / 2$, then $\pi_{t \prime \prime}^{*}$ decreases with $\alpha$ in $\left(0, \hat{\alpha}_{1}\right)$.

(d) If $\theta>-\lambda\left(c_{c}+v\right) / 2$, the relationship of the parameters might follow two cases: (d1) $0<\hat{\alpha}_{3}<\hat{\alpha}_{1}$ and (d2) $0<\hat{\alpha}_{1}<\hat{\alpha}_{3}$.

Case $(\mathrm{d} 1)$ holds if and only if $v>\max \left\{0,\left(\theta+2 \sqrt{-\theta_{\epsilon}}\right) / \lambda\right\}$, and in case $(\mathrm{d} 1) \pi_{t,}^{*}$ increases in $\left(0, \hat{\alpha}_{3}\right]$ and decreases in $\left[\hat{\alpha}_{3}, \hat{\alpha}_{1}\right)$. However, for case $(\mathrm{d} 2)$, there are no real parameters make it hold, thus omitted. 
Proof of Proposition 3

Substituting Equation (16) into Equations (4) and (5), and then combining with Equation (12), we can obtain:

$$
\pi_{t,}=\phi \Pi^{\circ}, \pi_{l n}=(1-\phi) \Pi^{\circ} \text {. }
$$

Since each player's profit is aligned with tourism supply chain's profit, the channel can be coordinated. Furthermore, to guarantee that each player's profit is Pareto improved under the quantity discount contract, parameter $\phi$ should satisfy $\phi \Pi^{\circ} \geq \pi_{l,}^{*}$ and $(1-\pi) \Pi^{\circ} \geq \pi_{t,}^{*}$, that is, $(1+\alpha \lambda) /(2+\alpha \lambda)^{2} \leq \phi \geq 1 /(2+\alpha \lambda)$.

Proof of Corollary 2

Substituting $q^{\circ \circ}$ into Equation (32), we can get:

$$
w-c_{l}=\frac{\phi c_{e}}{2}-\frac{\phi(1+\alpha \lambda(1-r))(\alpha \theta+v)}{2}+\frac{\alpha \theta+v}{2}+\frac{c_{e}}{2(1+\alpha \lambda(1-r))}-c_{l}-c_{l} .
$$

Based on Equations (A2) and (31), we can derive the condition under which $w<c_{\text {l }}$ holds:

$$
\frac{\left(\alpha \theta+v-2\left(c_{t}+c_{l}\right)\right)(1+\alpha \lambda(1-r))+c_{e}}{(1+\alpha \lambda(1-r))\left((\alpha \theta+v)(1+\alpha \lambda(1-r))-c_{e}\right)} \leq \phi \leq \frac{1}{2+\alpha \lambda(1-r)}
$$

And if the following inequality holds, there are not any real $\phi$ that makes (A3) hold:

$$
\alpha \theta+v-2\left(c_{t}+c_{l}\right)+\frac{c_{e}}{1+\alpha \lambda(1-r)}>\frac{(\alpha \theta+v)(1+\alpha \lambda(1-r))-c_{c}}{2+\alpha \lambda(1-r)} .
$$

Equation (A4) implies the conditions that $r$ should satisfy to curb OLC. 